\title{
Planteamiento jurídico de la separación judicial, el divorcio y la nulidad matrimonial de los ciudadanos ecuatorianos en España
}

\section{Introducción al marco de estudio}

En los últimos años la población ecuatoriana en España ha experimentado un crecimiento espectacular. Hoy en día, después de los ciudadanos marroquíes (263.174), la colonia ecuatoriana ocupa el segundo puesto de ciudadanos extranjeros en España con tarjeta o permiso de residencia en vigor (132.628), según los datos oficiales aportados por el último Balance de 2003 publicado por la delegación del gobierno para la Extranjería y la Inmigración sobre la base de la Dirección General de Ordenación de las Migraciones del Ministerio del Interior. ${ }^{1}$ No obstante, según las cifras que manejan diversas asociaciones de ciudadanos ecuatorianos y distintos organismos humanitarios se estima que extraoficialmente habría al menos el doble de ecuatorianos en territorio español. En todo caso, la colonia de inmigrantes procedentes de Ecuador es la primera y más numerosa de América latina, seguida de la colombiana, peruana, dominicana y la argentina. Si bien la situación de los ecuatorianos en España suscita muchas dudas en cuanto al estricto régimen jurídico de extranjería, también es cierto que surgen otras tantas derivadas de cuestiones específicas de Derecho Internacional Privado (DIPr), donde el Derecho de Familia internacional se torna fundamental.

La movilidad de los ecuatorianos, motivada por diferentes razones, no sólo se ha traducido en posibles mejoras sociales sino también en problemas laborales, familiares o de desarraigo. El desplazamiento ha provocado el crecimiento de los matrimonios mixtos, la residencia de los cónyuges en un país diferente al de su nacionalidad común y, en particular, la separación de la familia y el incremento de los casos de desunión conyugal. Con ello, son frecuentes las llamadas crisis matrimoniales. Esto es, la separación, el divorcio y las solicitudes de nulidad del matrimonio, ligadas a los consiguientes problemas jurídicos que su resolución comporta. ¿Cuál es el juez competente para decidir de una demanda planteada por un ecuatoriano residente en España en materia de divorcio? ¿Es susceptible de ser aplicada la normativa europea en esta materia? ¿Qué ley se aplica a la disolución conyugal de un matrimonio mixto formado por un español y una ecuatoriana? ¿Cuál es el procedimiento para reconocer en España las sentencias en materia de Derecho de familia dictadas por un juez ecuatoriano? Etc.

Estas cuestiones y muchas más que se irán planteando a lo largo del trabajo, serán aquí objeto de comentario. De manera que el presente documento pretende dar respuesta a una realidad de gran importancia práctica y actualidad centrada en la resolución, desde un punto de vista jurídico, de las crisis matrimoniales que afectan a los miles de ciudadanos ecuatorianos que viven en España. Desde esta perspectiva, el desarrollo del trabajo se guiará del modo siguiente:

- En primer lugar, desde un punto de visto normativo, se analizará la articulación legal de la nulidad matrimonial, la separación y el divorcio en el sistema español de DIPr. Para ello, se diferenciará la perspectiva europea o comunitaria en las cuestiones de crisis matrimoniales que aquí nos ocupan, de la perspectiva externa o extracomunitaria, en general, investigando si existen convenios bilaterales en esta materia que vinculen a España y Ecuador, para así precisar, en definitiva, cuál es la normativa que resulta de aplicación (Epígrafe II, apartados 1. A), B) y 2. A), B))

- En segundo lugar, se procederá a concretar, dentro de ésta última dimensión externa, las cuestiones de separación, nulidad y divorcio que afectan estrictamente a los ciudadanos/as ecuatorianos/as que se encuentran en España. Ello dará lugar a plantear problemas de foro o competencia judicial internacional, cuestiones de Derecho aplicable y problemas referidos al reconocimiento y ejecución de sentencias matrimoniales en España procedentes de Ecuador y viceversa (Epígrafes III, IV y V, respectivamente).

- A continuación, se procederá con un supuesto práctico para que tanto el afectado como el profesional del Derecho tengan una guía orientativa de cómo actuar en estos casos (Epígrafe VI). Para finalizar, se establecerán unas conclusiones a modo de breve resumen o análisis final del trabajo (Epígrafe VII).

El doble sistema de nulidad matrimonial, separación judicial y divorcio en el derecho internacional privado español

\section{Perspectiva general}

\section{A) Diferencia entre el régimen europeo comunitario y el régimen autónomo español}

El Derecho matrimonial ha sido objeto de importantes cambios en los últimos años por parte del legislador europeo. Cambios que, obviamente, han afectado en gran medida al sistema de Derecho Internacional Privado español en este ámbito. La incidencia de la normativa común en el sec- 
tor es tal que a partir de la entrada en vigor del Reglamento comunitario 1347/2000, de 29 de mayo, relativo a la competencia, reconocimiento y ejecución de resoluciones judiciales en materia matrimonial y de responsabilidad parental sobre hijos comunes, más conocido como el Reglamento de Bruselas II (RB II), ${ }^{2}$ normativa que en breve será sustituida por el Reglamento (CE) 2201/2003 del Consejo, de 27 de noviembre de 2003 , relativo a la competencia, el reconocimiento y la ejecución de resoluciones judiciales en materia matrimonial y de responsabilidad parental, por el que se deroga el Reglamento (CE) 1347/2000 (Nuevo RB II), ${ }^{3}$ se puede hablar de un régimen jurídico doble para el tratamiento de la nulidad matrimonial, la separación judicial y el divorcio en el sistema de DIPr español. En consecuencia, en España existe un régimen normativo diferenciado para determinar la competencia judicial internacional y regular la eficacia de las sentencias extranjeras dictadas en materia matrimonial.

Por un lado, se aplicará el Reglamento comunitario $1347 / 2000$, Bruselas II, teniendo en cuenta que, a partir del 1 de marzo de 2005, éste será efectivamente sustituido por el nuevo RB II, núm. 2201/2003 (art. 71 y 72). Normativa que sólo afecta a la competencia judicial internacional y al reconocimiento y ejecución de decisiones extranjeras dictadas en materia matrimonial. Se excluye aquí el sector del Derecho aplicable para el que no existe un convenio específico en este sentido. Las normas de competencia son susceptibles de amparar a un ciudadano ecuatoriano por el simple hecho de residir en un país europeo como España. Hecho que será suficiente para fundamentar la competencia de los jueces y tribunales españoles en la decisión de un supuesto de nulidad, separación o divorcio, aunque el cónyuge del ecuatoriano/a demandado/a se encuentre en un país no comunitario, por ejemplo y, como suele ser habitual, aquel hubiese permanecido en Ecuador. ${ }^{4}$ Sin embargo, en cuanto al reconocimiento de las decisiones dictadas en materia matrimonial, el Reglamento sólo se aplicará al reconocimiento de decisiones comunitarias en el ámbito europeo entre los Estados miembros. Por este motivo, ni Bruselas II ni el nuevo Reglamento de Bruselas II, podrá ser de aplicación para reconocer una sentencia de nulidad matrimonial, separación o divorcio dictada por un juez ecuatoriano ni de ningún otro país no comunitario. En éste último caso se habrá de acudir a la normativa autónoma de DIPr español destinada al reconocimiento y ejecución de decisiones extranjeras señalada a continuación.

Así pues, de otro lado, se aplicará el Régimen Autónomo o la normativa española interna de DIPr. Sistema contemplado, principalmente, en distintas disposiciones contenidas en diversos cuerpos legales. Estos son, la Ley Orgánica 6/1985, de 1 de julio, del Poder Judicial (LOPJ), ${ }^{5}$ el Código Civil (Cc) ${ }^{6}$ y la Ley $1 / 2000$, de 7 de enero, de Enjuiciamiento Civil (LEC). ${ }^{7}$ Normativa que, también, será diferente para cada uno de los sectores internacionalprivatistas afectados. Así:

1. En relación con los foros de competencia. Para determinar si jueces y tribunales españoles son competentes para conocer de un litigio internacional en materia matrimonial que afecte a un ecuatoriano/a, o a ambos, afincados en España, se aplicará el art. 22 de la Ley Orgánica del Poder Judicial. Foros que, en la actualidad como se comprobará más adelante, han sido en su mayoría inuti- lizados por la prevalencia en su aplicación del Reglamento de Bruselas II, tanto el nuevo como el anterior.

2. En cuanto al Derecho aplicable, será de aplicación el art. 9. 2 del Cc que, en lo que respecta a la separación y el divorcio, remite expresamente al art. 107 de dicho Código. Disposición que, también, recientemente ha sido reformada en el ordenamiento español por el artículo tercero de la Ley Orgánica 11/2003, de 29 de septiembre, de medidas concretas en materia de seguridad ciudadana, violencia doméstica e integración social de los extranjeros. ${ }^{8}$ Respecto a este particular hay que adelantar que la referida novedad legislativa no ha alterado en gran medida a los arts. 9.2 y $107 \mathrm{Cc}$. Ambos continúan refiriéndose a la ley aplicable a la nulidad matrimonial, la separación y el divorcio. Lo único que se ha renovado someramente es su contenido en el sentido de incorporar una nueva redacción más completa que la anterior.

3. En tercer lugar, para el reconocimiento en España de decisiones extranjeras no comunitarias en materia matrimonial y, en consecuencia, para el reconocimiento de decisiones procedentes de Ecuador en este ámbito, tradicionalmente era de aplicación el art. 107. II Cc que, a su vez, remitía al procedimiento estándar de exequátur contemplado en los antiguos arts. 951-958 de la Ley española de Enjuiciamiento Civil de 1881. Sin embargo, el antiguo art. 107. II ha sufrido una derogación en virtud de la mencionada Ley Orgánica 11/2003, de 29 de septiembre. En este sentido, el silencio observado en dicha Ley en cuanto a los efectos que producirán en el ordenamiento español las sentencias de divorcio dictadas por Tribunales extranjeros, al haberse derogado el segundo párrafo del anterior art. $107 \mathrm{Cc}$, permite deducir que en este aspecto se seguirá acudiendo al régimen general de reconocimiento y ejecución de sentencias. Se aplicará, en consecuencia, el Régimen Autónomo de reconocimiento y ejecución se decisiones extranjeras, arts. 951-958 LEC de 1881, todavía en vigor, al no haber sido derogado por la actual LEC $1 / 2000$, de 7 de enero (BOE núm. 7 de 8 de enero) que los excepciona en su disposición derogatoria hasta la vigencia de la Ley sobre cooperación jurídica internacional en materia civil. No obstante, la modificación ha venido por otra parte. En concreto, a partir de otras dos leyes muy distintas. Por un lado, el artículo 85.5 LOPJ, ha sido modificado por la Ley Orgánica 19/2003, de 23 de diciembre, de modificación de la Ley Orgánica 6/1985, de 1 de julio, del Poder Judicial (BOE, núm. 309, viernes 26 de diciembre de 2003). Ley que también ha suprimido el último párrafo del art. 958 LEC. Y, por el otro lado, el art. 955 de la LEC de 1881 ha sido modificado por la Ley 62/2003, de 30 de diciembre, de medidas fiscales, administrativas y del orden social (BOE, núm. 313, miércoles 31 de diciembre de 2003).9

\section{B) Ausencia de convenio bilateral entre España y Ecuador}

Una precisión se impone en cuanto a la aplicación del régimen autónomo español enunciado en el apartado anterior. Si bien, como es sabido, la legislación comunitaria europea prevalece sobre la normativa interna en aquellos casos en los que pueda ser aplicada, a las resoluciones procedentes de Estados no comunitarios con los que España haya 
ratificado algún convenio bilateral de asistencia judicial internacional, cooperación, competencia o reconocimiento y ejecución de sentencias, el convenio bilateral se aplica con preferencia al régimen autónomo. Ello ocurre en los siguientes supuestos en los que la sentencia provenga de Suiza, Colombia, República Checa, Eslovaquia, México, Israel, Brasil, Bulgaria, China, Rusia, Marruecos, Uruguay y Rumania. Países con los cuales España ha firmado un convenio bilateral sobre cooperación judicial para el mutuo reconocimiento de sentencias civiles y mercantiles entre ambos países. ${ }^{10}$

Convenio bilateral que, por ahora, no ha sido firmado entre España y Ecuador y por el que aquí se aboga para que pueda ser una realidad en un futuro no muy lejano aunque, por el momento, no exista nada previsto al respecto.

De todo lo expuesto se deduce que el sistema de nulidad matrimonial, separación judicial y divorcio existente en el DIPr español es doble. En este caso concreto no se contempla la posible incidencia de un convenio bilateral con Ecuador, hoy por hoy inexistente. Únicamente se ha de diferenciar el régimen interno de DIPr español señalado del sistema europeo contenido en el Reglamento $1347 / 2000$ y en el nuevo Reglamento de Bruselas II, 2201/2003. Normativa que dada su particular trascendencia y la reciente reforma que se hará efectiva el próximo 1 de marzo de 2005 (arts. 72 y 64 del nuevo Reglamento), será objeto de un breve comentario en el siguiente apartado.

\section{Incidencia particular de la legislación europea en materia matrimonial}

\section{A) Normativa comunitaria: evolución y cambios más recientes}

Al igual que lo sucedido con el incremento del número de ecuatorianos residentes en España y las consecuencias en cuanto al Derecho internacional de Familia que ello conlleva es evidente que, en la última década, también se ha producido un aumento considerable de las relaciones familiares y matrimoniales en la Unión Europea, efecto lógico de la consolidación de las libertades comunitarias y, en especial, de la mayor movilidad entre los ciudadanos de los Estados miembros. Con el incremento de las relaciones conyugales han aumentado el número de las crisis matrimoniales mixtas. Se han disparado los casos de divorcio, anulación y separación entre residentes comunitarios con las repercusiones que sobre la responsabilidad parental y los Derechos de visita ello implica. Por estos motivos, en Europa ha sido necesario llegar a un difícil consenso para lograr tener un Instrumento normativo común en esta materia y así poder superar los complicados problemas de competencia jurisdiccional y de reconocimiento y ejecución de sentencias. Sobre todo, el hecho tan recurrente en la práctica de que las partes implicadas en los procedimientos matrimoniales tiendan a buscar la jurisdicción más ventajosa para sus intereses entre todos los Estados miembros (el forum shopping) o intenten eludir las resoluciones judiciales o administrativas dictadas en un Estado pretendiendo que éstas sean anuladas en el suyo propio."

Normativamente hablando, resulta curioso que a pesar de la importancia del Derecho de familia, en general, y de su faceta matrimonial, en particular, es ésta una materia que tra- dicionalmente había sido obviada en los principales Instrumentos jurídicos comunitarios. El convenio europeo por excelencia, el Convenio de Bruselas de 27 de septiembre de 1968 relativo a la competencia judicial y a la ejecución de resoluciones judiciales en materia civil y mercantil (CB), ${ }^{12}$ rechazaba expresamente el tratamiento del Derecho de familia. En su art. 1.1 dispone que se excluirá de su ámbito de aplicación: El estado y la capacidad de las personas físicas, los regímenes matrimoniales, los testamentos y las sucesiones.

Ante esta grave ausencia de regulación comunitaria en un ámbito que cada vez tenía más trascendencia práctica surgió el Convenio celebrado con arreglo al art. $K 3$ del Tratado de la Unión Europea, sobre la competencia, el reconocimiento y la ejecución de resoluciones judiciales en materia matrimonial, hecho en Bruselas el 28 de mayo de 1998, denominado Convenio de Bruselas II (CB II). ${ }^{13}$ Sin embargo, aunque el mencionado Instrumento comunitario, procuró inaugurar la regulación del Derecho europeo de familia falló en su intento, al ser este un Tratado que pese a su publicación en el Diario Oficial de Comunidad Europea (DOCE), actual Diario Oficial de la Unión Europea (DOUE), nunca llegó a entrar en vigor.

Tuvo que ser inaugurado el nuevo milenio para que por fin se hiciera algo normativamente significativo al respecto. El 1 de marzo de 2001 entró en vigor el mencionado Reglamento 1347/2000, de 29 de mayo, conocido como el Reglamento de Bruselas II, dado que su origen se debió fundamentalmente a la integración de gran parte de los preceptos del anteriormente fallido CB II. El Reglamento 1347/2000 marcó un hito significativo en el Derecho europeo de familia al permitir, por vez primera, la existencia de una normativa común en materia matrimonial. Poco tiempo después el Reglamento (CE) núm. 44/2001 del Consejo, de 22 de diciembre de 2000, relativo a la competencia judicial, el reconocimiento y la ejecución de resoluciones judiciales en materia civil y mercantil ( $R$. 44) se sumó a la regulación de los aspectos relativos al Derecho de familia en cuestiones referidas al Derecho de alimentos. Sin embargo, volvió a eludir, al igual que antes lo hiciera el $\mathrm{CB}$, otras materias concretas tales como las relativas al estatus y la capacidad de las personas físicas, los regímenes matrimoniales, los testamentos y las sucesiones (art. 1.2 a). ${ }^{14}$

En la actualidad, resulta chocante que después de todo lo que ha tardado la Unión Europea en lograr un consenso normativo mínimo en Derecho de familia y siendo el Reglamento $1347 / 2000$ el único instrumento que se dedicaba a la competencia judicial internacional y al reconocimiento mutuo de decisiones comunitarias en materia matrimonial, se haya abogado recientemente por la derogación o reforma, de este último y por la modificación del R. 44, cuando ni tan siquiera hace dos años que ambos entraron en vigor.

En efecto, en el escaso margen de tiempo que el RB II lleva funcionando su eficacia ha sido cuestionada y varias veces puesta en entredicho, sobre todo en lo que se refiere al estrecho margen de acción que dejaba su reducido ámbito de aplicación. ${ }^{15}$ De ahí que, el 17 de mayo de 2002, la propia Comisión Europea presentó una Propuesta de Reglamento del Consejo con la finalidad de derogar el citado Reglamento: Propuesta de Reglamento del Consejo relativo a la competencia, el reconocimiento y la ejecución de resoluciones 
judiciales en materia matrimonial y de responsabilidad parental derogando el Reglamento (CE) núm. 1347/2000 y modificando el Reglamento (CE) núm. 44/2001 en materia de alimentos. ${ }^{16} \mathrm{Y}$, diez meses más tarde, el 14 de marzo de 2003, se publicaba en el DOCE el Dictamen del Comité Económico y Social sobre dicha Propuesta, ${ }^{17}$ recomendando, con especial intensidad, que toda la legislación comunitaria relacionada con la competencia, el reconocimiento y la ejecución de las resoluciones judiciales en materia matrimonial y de responsabilidad parental se reuniera en un único instrumento con el objeto de facilitar el trabajo de los jueces y los profesionales de la Justicia al tratar cuestiones sobre la responsabilidad parental que surgen a menudo en el contexto de procedimientos en materia matrimonial. De manera que, los cambios experimentados con la mencionada Propuesta de derogación del RB II no tratan sobre su eliminación sino sobre la integración de éste con otros instrumentos comunitarios de cara a aumentar su eficacia práctica. ${ }^{18}$

De este modo el actual Reglamento 1347/2000 tiene los meses contados, si bien con cierto retraso pues, como es sabido, el citado proceso de Reforma de Bruselas II se encontró durante un tiempo paralizado. En efecto, a pesar de que la pretendida Propuesta del Consejo para reformar Bruselas II iba a haber entrado en vigor el pasado 1 de julio de 2003 , para comenzar a ser aplicada el 1 de julio de 2004 , los plazos no se cumplieron. Finalmente, tras buscar el consenso con la Conferencia de la Haya, el 23 de diciembre de 2003, por fin se ha publicado en el DOUE el nuevo Reglamento de Bruselas II, núm. 2201/2003 relativo a la competencia, el reconocimiento y la ejecución de resoluciones matrimoniales y de responsabilidad parental, El nuevo Reglamento de Bruselas II, que entrará en vigor el 1 de agosto de 2004 y será aplicable a partir del 1 de marzo de 2005, a excepción de sus artículos 67, 68,69 y 70, que se aplicarán a partir del 1 de agosto de 2004 (art. 72).

\section{B) El nuevo Reglamento de Bruselas II: aspectos generales y ámbito de aplicación}

Como ha sido reiterado a lo largo del trabajo el actual Reglamento 1347/2000 tiene los días contados. El 1 de agosto de 2004 entrará en vigor el nuevo Reglamento de Bruselas II. La revisión de éste último ha sido prevista en el mismo. A más tardar, el 1 de enero de 2012, y a continuación cada cinco años, la Comisión presentará al Parlamento Europeo, al Consejo y al Comité Económico y Social Europeo un informe basado en la información proporcionada por los Estados miembros relativo a la aplicación del presente Reglamento, acompañado, si ha lugar, de propuestas encaminadas a su adaptación (art. 65). En consecuencia, y dado que el nuevo Reglamento de Bruselas II ha nacido con unas pretensiones de estabilidad y seguridad jurídicas no alcanzadas en sus predecesores, se ha considerado conveniente realizar una breve referencia a sus características más relevantes a efectos de su pronta aplicación.

El nuevo Reglamento de Bruselas II será aplicable a las acciones judiciales ejercitadas, a los documentos públicos con fuerza ejecutiva formalizados o registrados y a las transacciones celebradas ante el juez durante un proceso con posterioridad a su entrada en vigor de conformidad con el art. 72. El art. 64 es la disposición que se encargará de definir las cuestiones transitorias en cuanto a su aplicación. $\mathrm{Re}$ - gula únicamente la competencia judicial internacional y el reconocimiento y ejecución de resoluciones, entendidas éstas en un sentido amplio (fallo, decisión, sentencia, resolución, auto, etc.). Ahora bien, dado que la razón principal de su existencia se debe a las numerosas críticas que recibió desde su entrada en vigor el Reglamento 1347/2000, su principal particularidad no radica tanto en su novedad como en los aspectos que suponen un avance respecto al anterior. Entre estos destacan la ampliación del ámbito material del Reglamento y la introducción de la figura de las Autoridades Centrales en sede comunitaria. Así, el nuevo Reglamento comunitario ha merecido una valoración matizada en cuanto a las innovaciones que ha introducido. Si por una parte ha merecido una valoración positiva en cuanto a la mejora que ha supuesto en relación con la materia de la responsabilidad parental respecto al Reglamento 1347/2000 anterior, por otra parte, se han valorado negativamente los problemas de ajuste que supondrá su adaptación a las figuras ya existentes en el ordenamiento español. ${ }^{19}$ De otro lado, el nuevo RB II sigue excluyendo el sector del Derecho aplicable a estos procesos.

En la práctica, los pasos a seguir con el objeto de precisar el ámbito de aplicación del nuevo Reglamento de Bruselas II atienden básicamente a responder adecuadamente a tres sencillas preguntas: ¿De dónde procede la resolución que se pretende reconocer? (Ámbito de aplicación territorial). ¿En que fecha ha sido dictada ésta? (Ámbito de aplicación temporal). ¿De qué tipo de resolución se trata y si ésta es susceptible de ser reconocida y ejecutada? (Ámbito de aplicación material). De la respuesta a estas tres cuestiones se deduce que:

Por el momento, para los casos de separación, nulidad y divorcio procedentes de los Estados miembros de la Unión Europea, posteriores al 1 de marzo de 2001, se aplica el Reglamento 1347/2000, a excepción de Dinamarca. ${ }^{20}$ Ámbitos de aplicación territorial y personal que han mantenido los mismos criterios en el nuevo Reglamento de Bruselas II, teniendo en cuenta las fechas anteriormente indicadas en el ámbito de aplicación temporal, arts. 71 y 72 del nuevo Reglamento.

Sin embargo, para los supuestos en materia de crisis matrimoniales procedentes de los Estados miembros de la Unión Europea, anteriores al 1 de marzo de 2001, y de aquellos que, con independencia de la fecha, procedan de Dinamarca y de terceros Estados (como es el caso de Ecuador) así como al reconocimiento de las cuestiones conexas a la disolución del vínculo matrimonial (culpa de los cónyuges, aspectos económicos, alimentos, etc.) independientemente de la fecha y lugar de procedencia, se aplica el art. 107. Cc, recientemente reformado por la Ley Orgánica 11/2003, de 29 de septiembre. Disposición que conduce a la aplicación del Régimen Autónomo de reconocimiento y ejecución se sentencias extranjeras, arts 951-958 LEC de 1881, todavía en vigor, al no haber sido derogado por la actual LEC 1/2000, de 7 de enero que, como se ha comentado, los excepciona en su disposición derogatoria, hasta la vigencia de la Ley sobre cooperación jurídica internacional en materia civil, a excepción de las mencionadas reformas de los artículos 955 y 958 de la LEC. Se aplicará así el régimen interno que, en cuestión de competencia, remitirá al art. 22 
LOPJ, excepto en los casos en que se pueda aplicar el Reglamento $1347 / 2000$, o cuando comience a ser de aplicación, el nuevo Reglamento de Bruselas II núm. 2201/2003."1

\section{Competencia judicial internacional de jueces y tribunales españoles para decidir sobre demandas de nulidad matrimonial, separación judicial o divorcio presentada por ciudadanos ecuatorianos/as residentes en España}

En lo que atañe a nuestro objeto preciso de estudio, referido a Ecuador, dos son las cuestiones que sucesivamente se han de plantear, bien por separado o de común acuerdo, a la hora de instar la nulidad matrimonial, la separación judicial o el divorcio de los cónyuges de nacionalidad ecuatoriana residentes en España. La primera, cuál es la competencia judicial internacional para conocer del asunto. Es decir, si son competentes los Jueces y tribunales españoles, los ecuatorianos o, si cabe, los de un tercer Estado. La segunda, cuál es la legislación sustantiva aplicable a la nulidad matrimonial, a la separación judicial y al divorcio en estos casos.

\section{Dualidad en la delimitación}

En relación con la primera cuestión se ha de atender, de cara a su delimitación, al doble régimen jurídico anteriormente enunciado que en estos supuestos contempla el sistema español de DIPr.

De un lado, el artículo 3. 1 del nuevo Reglamento de Bruselas II, ex. art. 2 R. 1347/200, establece dentro de la competencia general en asuntos relativos al divorcio, la separación judicial y la nulidad matrimonial, siete foros de competencia, según los cuales serán competentes para resolver sobre las cuestiones relativas al divorcio, a la separación judicial o a la nulidad del matrimonio de los cónyuges los órganos jurisdiccionales del Estado miembro de la Unión Europea, como es el caso de España,

\section{a) En cuyo territorio se encuentre-}

La residencia habitual de los cónyuges, $o$

el último lugar de residencia habitual de los cónyuges, siempre que uno de ellos aún resida allí, o

- la residencia habitual del demandado, o

- en caso de demanda conjunta, la residencia habitual de uno de los cónyuges, $o$

a residencia habitual del demandante si ha residido allí desde al menos un año inmediatamente antes de la presentación de la demanda, $o$

a residencia habitual del demandante, si ha residido allí al menos los seis meses anteriores a la presentación de la demanda y o bien es nacional del Estado miembro en cuestión o, en el caso del Reino Unido y de Irlanda, tiene allí su domicile. ${ }^{22}$

\section{b) De la nacionalidad de ambos cónyuges o, en el caso del Reino Unido e Irlanda, del domicile de ambos cónyuges}

De otro lado, para el ámbito extracomunitario, normativa en principio más indicada para ser invocada en el caso de Ecuador, se aplicarán los foros de competencia previstos en el art. 22 LOPJ. Disposición que señala los casos en los que pueden conocer de un asunto relativo a la nulidad matrimonial, a la separación judicial y a un divorcio, los jueces y tribunales españoles.

Dos precisiones en este sentido. En primer lugar, hay que matizar que en España los foros en materia de crisis matrimoniales sólo habilitan a los tribunales españoles a conocer concretamente sobre la materia estricta de la crisis matrimonial, pero no en relación con otros aspectos colaterales aunque de trascendental importancia que suelen decidirse conjuntamente, tales como la custodia de los hijos, el pago de los alimentos a los hijos y la pensión que se deberá pasar al cónyuge, el régimen económico del matrimonio, etc. A cada una de estas cuestiones se deberá aplicar un régimen normativo autónomo e independiente. En segundo lugar, la normativa contemplada en el art. 22 LOPJ no indica la competencia territorial interna. Es decir, qué juzgado o tribunal es el competente por razón del territorio, el Juzgado de Primera Instancia de Madrid, de Salamanca, Badajoz, Valencia, Bilbao, etc. Únicamente se refiere a la competencia judicial internacional en general, no a la territorial, en particular. Para determinar ésta última se utiliza como regla general el criterio de la competencia territorial recogido en el art. 50, Fuero General de las Personas Físicas de la LEC y, también, en el art. 769 LEC que hace competente al juez del domicilio del actor en España, en virtud del cual, el criterio de la residencia habitual del demandante o actor sirve como foro de competencia territorial. De modo que, si el actor que pretende la separación judicial, la nulidad o el divorcio reside en Madrid, será competente el Juez de Primera Instancia de Madrid del partido correspondiente. ${ }^{23}$

Si después de aplicar los foros de competencia del art. 22 LOPJ, son definitivamente competentes los tribunales españoles para conocer sobre el fondo del asunto, también lo serán para dictar las medidas cautelares que consideren oportunas en el proceso, en virtud del artículo 22. 5 LOPJ.

\section{Desactivación de los foros de competencia españoles por el Reglamento de Bruselas II}

En virtud de lo expuesto en el apartado anterior, serán competentes los jueces y tribunales españoles para decidir sobre una demanda de nulidad matrimonial, separación judicial o divorcio presentada por un ciudadano/a ecuatoriano/a residente en España, o bien por una demanda conjunta presentada por ambos, en los siguientes casos:

1. Cuando ambos cónyuges posean la residencia habitual en España al tiempo de la demanda (art. 22. 3 LOPJ). Es decir, en los casos en los que el matrimonio ecuatoriano inste una demanda conjunta de separación judicial, nulidad matrimonial o divorcio en España, serán judicialmente competentes los jueces y tribunales españoles en virtud del art. 22. 3 LOPJ. Foro que responde al principio de proximidad del supuesto con el Estado español. 
No obstante, este foro de competencia ha sido desactivado por el Reglamento 1347/2000, así como por su sucesor, siempre y cuando la demanda sea posterior al $1 \mathrm{de}$ marzo de 2001, pues, según Bruselas II, la residencia habitual del demandado en España es foro de competencia suficiente para la aplicación del mencionado Reglamento comunitario, art. 2. 1 a) RB II, art. 3.2 a) del nuevo Reglamento de Bruselas II..$^{24}$

2. Cuando los cónyuges tengan nacionalidad española, sea cual sea su residencia, siempre que se promueva la petición de mutuo acuerdo o por uno con consentimiento de otro (Art. 22. 3 LOPJ). Foro que también queda desactivado o inutilizado por el Reglamento 1347/2000, art. 2. 1 b) RB II y por el nuevo Reglamento de Bruselas II, art. 3. 1 a). Este foro afectaría a los ecuatorianos que habiendo adquirido la nacionalidad española por cualquiera de las causas de adquisición o atribución de la nacionalidad, ${ }^{25}$ regresen después a su país de origen, es decir, a Ecuador y, una vez allí, pretendan de manera consensuada, la nulidad, el divorcio o la separación. Aún residiendo en Ecuador, podrían optar por la competencia judicial internacional de los Jueces españoles y la aplicación del Reglamento comunitario. Supuesto que, aunque podría darse en la práctica, como es de suponer por las dificultades procesales que conlleva no será uno de los más frecuentes.

3. Cuando el demandado/a ecuatoriano/a tenga su domicilio en España (art. 22. 2 LOPJ). Foro desactivado también por el Reglamento de Bruselas II, que admite el foro de la residencia habitual del demandado, art. 2. 1 a) tercer guión y su correlativo en el art. 3 del nuevo RB II. Es éste un foro importante de cara a la problemática de los permisos de residencia de los ecuatorianos en España. Es decir, a la tenencia de los ansiados papeles, ya que el presente foro de competencia exime de la tenencia de la residencia habitual en España a un ecuatoriano/a que se quiera separar, divorciar o solicitar la nulidad del matrimonio en nuestro país. Basta que el demandado viva habitualmente en España (art. 40 Código Civil español). Sin que sea preciso exigir que esté inscrito en los Registros Públicos o en el Padrón Municipal de un determinado Ayuntamiento del territorio español. ${ }^{26}$

4. Independientemente de la nacionalidad, en los casos en que ambos cónyuges se hayan sometido a los tribunales españoles (art. 22. 2 LOPJ). De este modo, si dos cónyuges ecuatorianos se quieren someter voluntariamente a los Tribunales españoles, será un supuesto de sumisión que ampara la legislación española. En este punto la doctrina insiste en realizar una importante matización. He aquí un foro de competencia judicial internacional que ha sobrevivido a la aplicación del Reglamento comunitario de Bruselas II y que sobrevivirá también al nuevo Reglamento de Bruselas II. Ello es debido a que los citados Reglamentos no acogen la sumisión. En consecuencia, la sumisión en materia de nulidad matrimonial, separación judicial y divorcio prevista en el art. 22 . 2 LOPJ, tiene un alcance general que no altera a ningún principio básico del sistema de DIPr español en materia matrimonial y así es admitido tanto doctrinal, ${ }^{27}$ como jurisprudencialmente. ${ }^{28}$
En conclusión, tanto el Reglamento de Bruselas II como de manera lógica y continuista el nuevo Reglamento de Bruselas II han desactivado muchos de los foros de competencia contenidos en el art. 22 LOPJ (Supuestos 1.2 y 3). De ahí que, en materia de competencia judicial internacional en el ámbito de crisis matrimonial, la normativa europea comunitaria también es susceptible de ser aplicada a supuestos extracomunitarios. Se puede aplicar a un ciudadano ecuatoriano residente en España o que simplemente viva habitualmente en nuestro país, con el objetivo de no dar lugar a una discriminación en los criterios de aplicación personal del RB II por razón de la nacionalidad. ${ }^{29}$ Así, se admite, como criterio general, la competencia de los tribunales españoles sobre la base de la mera residencia habitual en España del actor de la demanda de nulidad, separación o divorcio. Criterio que encaja a la perfección con uno de los principios que con más fuerza rigen el Derecho matrimonial internacional, el del Favor divortii, también contemplado en el art. 85 Cc español y en la aplicación de los criterios de competencia judicial internacional del Reglamento de Bruselas II, tanto antes como después de la reforma.

\section{Derecho aplicable}

\section{Legislación sustantiva: recientes modificaciones legislativas}

En cuanto a la segunda cuestión relativa al Derecho aplicable a estos procesos es importante precisar que la mencionada modificación de la normativa española a los supuestos matrimoniales internacionales comprende todos los casos. Es decir, el aplicador del Derecho tendrá que tener en cuenta que la reciente reforma legislativa se hará notar tanto en el ámbito comunitario europeo como en el extracomunitario, puesto que hay que recordar que el mencionado Reglamento de Bruselas II sólo atañe a la competencia judicial internacional y al reconocimiento y ejecución de sentencias procedentes de países miembros, pero no comprende la legislación sustantiva aplicable; donde, a falta de un convenio internacional al respecto, se ha de recurrir a los arts. 9. 2 y 107 del CC que, como se ha especificado, en España han sido recientemente reformados por el artículo tercero de la Ley Orgánica 11/2003, de 29 de septiembre.

En primer lugar, resulta de aplicación el apartado 2 del artículo 9 del Cc. Disposición que en materia de separación judicial y divorcio, y que ahora tras la reforma también incorpora la nulidad del matrimonio, hace una remisión expresa al art. 107 del mismo Código. Norma de conflicto específica en el sistema de DIPr español en virtud de la cual, tras la modificación, será de aplicación:

- A la nulidad del matrimonio y sus efectos: la Ley aplicable a su celebración $(107.1 \mathrm{Cc})$.

A la separación judicial y al divorcio se aplicará (art. 107. $2 \mathrm{Cc}$ ): la Ley nacional común de los cónyuges al tiempo de presentación de la demanda; a falta de nacionalidad común, a la Ley de la residencia habitual común del matrimonio en dicho momento y, en defecto de ésta, a la Ley de la última residencia habitual común del matrimonio si uno de los cónyuges aún reside habitualmente en dicho Estado. Supuesto, este último, que ha sido incorporado tras la modificación actual. También se ha 
añadido el siguiente apartado: En todo caso, se aplicará la Ley española cuando uno de los cónyuges sea español o resida habitualmente en España:

a) Si no resultara aplicable ninguna de las leyes anteriormente mencionadas.

b) Si en la demanda presentada ante el tribunal español la separación o el divorcio se pide por ambos cónyuges o por uno con el consentimiento del otro.

c) Si las leyes indicadas en el párrafo primero de este apartado no reconocieran la separación o el divorcio o lo hicieran de forma discriminatoria o contraria al orden público.

En atención a la primera conexión, que en la práctica es la más frecuente, si en el momento de presentar la demanda la nacionalidad común de los cónyuges es la de un país extracomunitario, por ejemplo Ecuador, ésta será la ley que habrá de aplicar el juez español. Dando por sabido que la ley extranjera mencionada será de aplicación a los aspectos sustantivos de la separación, nulidad o divorcio, pero no a los procesales, ya que si el proceso se sigue en España, la ley aplicable al mismo es la española. En el caso de que la Ley aplicable fuera, por ejemplo, la de un país que no admitiera la separación o el divorcio, es muy probable que en este supuesto dicha Ley pudiera considerarse discriminatoria o contraria al orden público español. De ahí que, para eludir su aplicación, se podría recurrir al apartado c) del art. 107. 2 Cc. Hecho que llevaría finalmente a aplicar el Derecho español. Con ello, se da respuesta a una problemática que había sido denunciada de manera sistemática ante el Defensor del pueblo español por considerar que se conducía a la indefensión a muchas de las mujeres extranjeras, en especial de nacionalidad marroquí, que solicitaban la separación o el divorcio en nuestro país. Según éstas críticas el desamparo se producía porque al remitirse a la ley común que era la aplicable se encontraban con que no se podían separar ni divorciar debido a que en su país de origen ni el divorcio ni la separación se encontraban reconocidos.

Con la reforma del art. 107, se intentan superar los límites que suponía la aplicación de la ley nacional común al primar el interés de la persona que pretende lograr la separación o el divorcio (Exposición de Motivos, considerando IV-4\%). El artículo $107.2 \mathrm{c}$ ) da preferencia a la ley española sobre aquella designada aplicable si ésta última no reconociera la separación o el divorcio, o en caso de hacerlo, fuera de manera discriminatoria o contraria al orden público. ${ }^{30}$ La nueva redacción dispositiva ha plasmado una solución normativa específica para estos casos cuando no hubiera hecho falta, pues también se hubiera podido eludir la aplicación de la ley extranjera discriminatoria por su contrariedad con el orden público utilizando el mecanismo que el sistema español de DIPr ya tiene previsto para estos casos. Es decir, acudiendo al art. 12.3 Cc como cláusula de exclusión de la Ley extranjera por motivos de orden público. De otro lado, según nuestra doctrina y el silencio manifestado en nuestro Código civil se deduce una consecuencia importante. La imposibilidad de plantear la sumisión expresa de los cónyuges a la ley española.

Cosa distinta es que, en la práctica, la aplicación del Derecho ecuatoriano pueda plantear un problema de prueba ante el Juez español. En este caso, por mandato del art. 281. 2 LEC, el interesado es el que deberá probar el Derecho ecuatoriano, en lo que respecta a su contenido y vigencia, sin perjuicio de que el Tribunal español competente pueda valerse de cuantos medios de averiguación considere necesarios para su aplicación. Dependiendo de la dificultad para comprobar la vigencia del Derecho extranjero en cuestión, sería posible y muy razonable solicitar la práctica de prueba consistente en que por medio de una comisión rogatoria, a través del conducto oficial de la Subdirección General de Cooperación Judicial Internacional del Ministerio de Justicia español, se proceda a verificar la mencionada vigencia del Derecho extranjero al Ministerio de Asuntos Exteriores de Ecuador.

\section{Posibilidad de reenvío de retorno a la ley española}

No obstante lo anterior, se impone una precisión en cuanto a la aplicación de la ley ecuatoriana por el Juez o tribunal español en ciertos supuestos en los que se puede plantear la posibilidad de un reenvío de retorno o reenvío de primer grado a la ley española. Ello podría articularse en uno de los casos más frecuentes en la práctica: aquel en el que los dos protagonistas de la crisis matrimonial, los dos cónyuges, continúen teniendo la nacionalidad ecuatoriana al plantear la demanda. La residencia es aquí irrelevante. No importa que el domicilio conyugal se encuentre en España o que uno de los cónyuges resida en Ecuador y el otro en el Estado español. Lo que importa es que sobre la base de la primera conexión de la legislación sustantiva aplicable será de aplicación la ley nacional común de los cónyuges al tiempo de la presentación de la demanda, art. $107 \mathrm{Cc}$ español. Pues bien, si la ley española contiene en ésta disposición una norma conflictual que determina la aplicación de la ley nacional común de los cónyuges en el momento de presentar la demanda, en este caso la ley ecuatoriana, y nos dirigimos a lo prescrito por la misma, se ha de tener en cuenta el Derecho ecuatoriano en su conjunto, tanto el material como el conflictual.

Una vez en la legislación ecuatoriana puede darse que en los casos de separación judicial y divorcio exista también un reenvío a la ley del país donde se encontrarán los cónyuges. En consecuencia, la ley española podría ser finalmente la aplicable en el estricto supuesto en que los dos cónyuges de nacionalidad ecuatoriana tuvieran su domicilio conyugal en España. En este reenvío de retorno a la ley española la remisión se produce al Derecho español, pero ya no al derecho conflictual, sino al Derecho material que declara aplicable la normativa española de separación judicial y divorcio (art. 12. 2 Cc español).

En todo caso, en España hay que matizar que en la práctica todo dependerá de la aceptación o no del reenvío por el juez competente en ese momento. Como es sabido, la contradicción inherente en el art. 12. 2 Cc español y su marcado carácter nacionalista sólo ha derivado en una reducida jurisprudencia y la escasa que existe al respecto es extraordinariamente vacilante y contradictoria. Sin embargo, es también conocido que existen supuestos en los que la jurisprudencia ha negado tradicionalmente los casos de reenvío y otros en los que se considera bastante aceptado. Nuestro objeto de estudio se encuentra dentro de este último grupo al haberse defendido la proyección del reenvío sobre ciertas 
cuestiones derivadas del estatuto personal. En particular, a la capacidad, a las sucesiones y a los regímenes matrimoniales que aquí nos ocupan. ${ }^{31}$ Además, en este caso se defiende la admisión de un reenvío de primer grado que declararía aplicable la ley española porque, como señalaba A. Pérez Voituirez, la respuesta a la cuestión del rechazo o aceptación del reenvío debería desenvolverse dentro de la idea de búsqueda de la vinculación más estrecha de la situación con uno de los ordenamientos implicados. ${ }^{32}$ Por tanto, en el caso en el que los dos cónyuges se encontrasen en España es claro el cumplimiento en sentido positivo de este requisito que llevaría a aceptar el reenvío a la ley española.

\section{Reconocimiento y ejecución en \\ España de decisiones matrimoniales procedentes de Ecuador}

El tercer sector de DIPr afectado, esto es, la cuestión de la eficacia en España de las sentencias ecuatorianas en materia de nulidad, separación judicial y divorcio, se regula, al igual que en el caso de la competencia judicial internacional, atendiendo a un doble régimen jurídico. De un lado, a las resoluciones procedentes de la Unión Europea posteriores al 1 de marzo de 2001, excepto las danesas, se aplica el Reglamento 1347/2000. Así, hasta el 1 de marzo de 2005. Fecha a partir de la cual será de aplicación el nuevo Reglamento de Bruselas II núm. 2201/2003. Para el resto de resoluciones procedentes de Ecuador, en particular, y de Terceros Estados no europeos, en general, se aplicaba el art. 107. II Cc, que remitía al procedimiento general de la LEC. Sin embargo, como ya se ha señalado, el silencio observado en la Ley Orgánica 11/2003 en cuanto a los efectos que producirán en el ordenamiento español las sentencias de divorcio dictadas por Tribunales extranjeros, al haberse derogado el segundo párrafo del anterior art. $107 \mathrm{Cc}$, permite deducir que en este aspecto se seguirá acudiendo al régimen general de reconocimiento y ejecución de sentencias. Se aplicará, en consecuencia, el Régimen Autónomo de reconocimiento y ejecución se decisiones extranjeras, arts 951-958 LEC de 1881 , todavía en vigor, a excepción de las disposiciones que han sido recientemente modificadas, arts. 955 y 958 LEC.

En consecuencia, para el reconocimiento y la ejecución en España de las decisiones dictadas en procesos relativos a supuestos de crisis matrimoniales ecuatorianas se aplica el procedimiento estándar de exequátur contemplado en los arts. 951 y siguientes de la LEC, que contienen, a su vez, dos sistemas de reconocimiento. Uno, el sistema de reciprocidad, arts. 952-953 LEC. Y, el otro, el sistema de condiciones, contenido en el art. 954 LEC. El novedoso e importante aspecto que ha cambiado en ambos es el órgano competente para reconocer una sentencia dictada por un juez ecuatoriano en materia de nulidad matrimonial, separación judicial y divorcio. Cambio particularmente relevante dado que hasta la fecha el órgano competente era el Tribunal Supremo español, según el art. 955. I LEC, en un procedimiento que en la práctica venía tardando entre año y año y medio. No obstante, gracias a la reforma del art. 955 de la LEC modificado por la Ley 62/2003 se establece que: Sin perjuicio de lo dispuesto en los tratados y otras normas internacionales, la competencia para conocer de las solicitudes de reco- nocimiento y ejecución de sentencias extranjeras corresponde a los Juzgados de Primera Instancia del domicilio o lugar de residencia de la parte frente a la que se solicita el reconocimiento o ejecución, o del domicilio o lugar de residencia de la persona a quien se refieren los efectos de aquellas; subsidiariamente la competencia territorial se determinará por el lugar de ejecución o donde aquellas sentencias y resoluciones deban producir sus efectos. Asimismo, el art. 85.5 LOPJ modificado por la Ley Orgánica 19/2003, establece que: Los Juzgados de Primera Instancia conocerán en el orden civil: De las solicitudes de reconocimiento y ejecución de sentencias y demás resoluciones judiciales y arbitrales extranjeras, a no ser que, con arreglo a lo acordado en los tratados y otras normas internacionales corresponda su conocimiento a otro juzgado o tribunal.

En todo caso, las condiciones básicas del reconocimiento siguen siendo las mismas. Es decir, las contempladas en el art. 954 LEC: a) que la sentencia extranjera no sea contraria al orden público internacional español; b) que ésta no se oponga a otra dictada en el mismo asunto por tribunales españoles; c) que se controle la competencia del juez de origen que ha dictado la sentencia; d) que la sentencia extranjera sea auténtica y; e) que el procedimiento llevado a cabo en el extranjero no haya vulnerado los derechos de defensa del demandado. Si la ejecutoria se deniega se devolverá al país que la hubiera presentado, en este caso Ecuador, según el art. 958 LEC, habiendo sido el último párrafo de este artículo suprimido por la Ley Orgánica 19/2003.

En parangón con el sistema general de reconocimiento y ejecución que acaba de ser sumariamente descrito en los antiguos preceptos de la LEC, es fácil comprobar como las ventajas que ha aportado Bruselas II son numerosas en éste ámbito. ${ }^{33}$ A partir de su entrada en vigor, todos los Estados europeos tienen una misma normativa para reconocer las sentencias matrimoniales procedentes de otro Estado miembro. Normativa que al estar unificada y dar muchas facilidades, ya que sirve al objetivo de la libre circulación de sentencias matrimoniales en todo el territorio comunitario, responde a una articulación sistemática sencilla, cómoda y rápida. Los tipos o sistemas de reconocimiento previstos en el Reglamento son varios dependiendo del efecto que se pretenda conseguir. El primero, el reconocimiento automático, que puede ser de dos tipos: judicial (art. 14. 1 RB II, art. 21. 1 nuevo RB II) y registral (art. 14. 2 RB II, art. 21. 2 nuevo $\mathrm{RB}$ II). El segundo, el reconocimiento principal (art. 14. 3 RB II, art. 21.3 nuevo RB II). Y, por último, el reconocimiento incidental (art. 14. 4 RB II, art. 21. 2 nuevo RB II). De entre ellos, la peculiaridad principal de Bruselas II es la comunitarización del denominado reconocimiento automático que ha suprimido el requisito, hasta entonces obligatorio, de obtener un previo exequátur ante el Tribunal Supremo. Exequátur que, como se ha especificado, ahora, tras la modificación operada por la Ley Orgánica 62/2003 sobre el art. 955 LEC, en España sería ante el Juzgado de Primera Instancia correspondiente según la citada disposición.

Hoy, en los países europeos, es posible invocar directamente la resolución matrimonial extranjera ante cualquier órgano jurisdiccional o Registro público, dependiendo de si el reconocimiento automático es judicial o registral. En la práctica, este último es el más frecuente, al ser el efecto constitutivo y su consecuencia registral el efecto más busca- 
do por el ciudadano europeo. Sin duda, a partir del RB II es claro que la aplicación del reconocimiento automático ha comportado un ahorro de tiempo y de dinero, al procederse a la actualización de las actas del Registro civil sin ninguna otra decisión previa ni tener que esperar el visto bueno del TS ni de ningún otro tribunal. ${ }^{34}$ Como se puede comprobar Bruselas II ha suprimido muchos de los trámites que anteriormente dificultaban la libre circulación de sentencias en este ámbito. De ahí lo conveniente que sería tener un Convenio similar con Ecuador en este marco de cara a obtener un reconocimiento automático de sentencias matrimoniales entre ambos países, sin previo procedimiento de exequátur.

\section{Supuesto práctico: Guía orientativa de los pasos a seguir ante la presentación en España de una demanda de divorcio por ciudadanos/as ecuatorianos/as}

Una vez analizados los tres sectores internacionalprivatistas afectados en relación con la nulidad matrimonial, la separación judicial y el divorcio y las soluciones a los problemas jurídicos que de ellos se derivan para los miles de ciudadanos ecuatorianos/a que se encuentran en España, a continuación, se ha considerado conveniente aplicar parte de lo examinado en la práctica. Para ello, qué mejor que proceder con un supuesto fáctico. A partir de él se indicarán los pasos a seguir para instar una demanda de divorcio ante un juez español y la determinación del Derecho aplicable a la misma. El propósito que se pretende con esta actuación es que a través de la lectura de la demanda se obtenga de manera fácil y completa cualquier otro tipo de información sobre la que no se haya incidido en particular, pretendiendo, así, despejar muchas de las dudas que se plantean de lege ferenda.

Supongamos, por ejemplo, el caso de Dña. María G.R., mujer de nacionalidad ecuatoriana casada con el nacional ecuatoriano D. Miguel P.N. desde 1990 y con cuatro hijos en común. Dña. María reside en Madrid desde 1994. En 1996 pudo traerse a España al resto de su familia gracias a un permiso de reagrupación familiar y estableció el domicilio conyugal en la calle Salitre núm. 6, distrito de La Latina en Madrid. Tras cinco meses en España el marido decide ir a trabajar a Francia desde donde envía dinero regularmente a su familia por un período de ocho meses. Sin embargo, poco tiempo después su familia deja de recibir noticias suyas enterándose por distintos medios que éste había regresado a Ecuador. El 8 de enero de 2004, Dña. María, habiendo adquirido la nacionalidad española, decide formalizar su situación conyugal y presenta demanda de divorcio ante el Juzgado de Primera Instancia de Madrid, contra su cónyuge, residente en Ecuador. La competencia de los jueces y tribunales españoles podría fundamentarse sobre la base del art. 2.1 a) del Reglamento de Bruselas II núm. 1347/2000 articulándose la demanda del modo señalado en el cuadro de la próxima página.

\section{Análisis final}

La solución a las cuestiones jurídicas consustanciales a las crisis matrimoniales de los ciudadanos ecuatorianos en España encuentran un marco legal en el sistema español de DIPr que, aunque no es todo lo adecuado que sería de desear es, al menos, suficiente. En el ordenamiento español existe un régimen normativo doble para determinar la competencia judicial internacional y regular la eficacia de las sentencias extranjeras dictadas en materia matrimonial. En concreto, la dualidad se refleja, con especial intensidad, en el tratamiento de la nulidad matrimonial, la separación judicial y el divorcio. Por un lado, a partir del 1 de marzo de 2001, se viene aplicando el Reglamento comunitario $1347 / 2000$, Bruselas II. Normativa que en breve será sustituida por el nuevo Reglamento de Bruselas II, núm. 2201/2003, que tiene previsto comenzar su aplicación efectiva el 1 de marzo de 2005. En todo caso, ambas normativas sólo afectarán a la competencia judicial internacional y al reconocimiento y ejecución de decisiones extranjeras dictadas en materia matrimonial, excluyéndose el sector del Derecho aplicable para el que no existe un convenio específico en éste ámbito. De otro lado, se aplicará el Régimen Autónomo o la normativa española interna de DIPr. Sistema contemplado, principalmente, en varias disposiciones procedentes de distintos cuerpos legales. En concreto, en el art. 22 LOPJ para la competencia judicial internacional, sobre todo en los casos de sumisión; en los arts. 9.2 y $107 \mathrm{Cc}$, reformados por la Ley Orgánica 11/2003, para el Derecho aplicable; y en los arts 951 al 958 de la antigua LEC de 1881 en el sector del reconocimiento y la ejecución, con las modificaciones señaladas en los artículos 955 y 958 .

Tomando como referencia la normativa existente, dos son las cuestiones que sucesivamente se han planteado a la hora de instar la nulidad matrimonial, la separación judicial o el divorcio de dos cónyuges de nacionalidad ecuatoriana residentes en España. La primera, cuál es la competencia judicial internacional para conocer del asunto. Es decir, si son competentes los Jueces y Tribunales españoles. Y, la segunda, cuál es la legislación sustantiva aplicable a la nulidad, separación o divorcio. En primer lugar, para determinar si los jueces y tribunales españoles son competentes para conocer de un litigio internacional en materia matrimonial que afecte a un ecuatoriano/a, o a ambos, afincados en nuestro país, se ha aplicado el art. 22 LOPJ. Normativa que, como se ha visto, a pesar de establecer de manera tradicional los foros de competencia en esta materia ha quedado en gran parte relegada. Ello se debe a que, en la práctica, muchas de las disposiciones del Reglamento comunitario de Bruselas II han desactivado los foros españoles de competencia. En consecuencia, como se ha observado, para justificar la competencia de los jueces y tribunales españoles será posible la aplicación de la normativa europea a un ecuatoriano/a, o a ambos cónyuges ecuatorianos, que insten la nulidad matrimonial, la separación judicial o el divorcio en España.

En cuanto al Derecho aplicable, se ha aplicado el art. 9. 2 del Cc que, en lo que respecta a la nulidad matrimonial, separación judicial y al divorcio, remite expresamente al art. 107 de dicho Código reformado por la Ley Orgánica 11/2003, de 29 de septiembre. Finalmente, para el reconocimiento en España de decisiones extranjeras no comunitarias 


\section{Instancia al Juzgado de Primera Instancia}

Don (...) Procurador de los Tribunales, con domicilio en esta ciudad, Calle....., en nombre y representación de Dña. María G.R., cuyas circunstancias personales son las siguientes $(. .$.$) y cuya representación procesal se forma-$ lizará mediante comparecencia apud acta, una vez concretado el Juzgado al que por turno de reparto le corresponda la presente demanda, ante el Juzgado comparezco y como mejor proceda en Derecho y bajo la dirección técnica de D. (...) Abogado del Ilustre Colegio de Abogados de Madrid, Colegiado número (...) y con despacho profesional en (...)

\section{Digo}

Que en la representación indicada y por medio del presente escrito, formulo DEMANDA DE DIVORCIO CONTENCIOSO entre mi representada contra su cónyuge D. Miguel P.N., cuyas circunstancias personales son (....) extranjero y con actual domicilio en Ecuador. Demanda que tiene su fundamento en los siguientes

\section{Hechos}

Primero: Mi mandante y su esposo contrajeron matrimonio civil el día (...) en Ecuador, matrimonio que fue inscrito en el Registro Civil de la ciudad (...), en el Tomo y página (...). Se acompaña a la presente, certificado de la inscripción del referido matrimonio expedido por el Registro Civil de la citada localidad.

Segundo: De dicho matrimonio han nacido cuatro hijos, cuyas circunstancias son las que siguen (...)

Tercero. Que debido a los desacuerdos producidos en el matrimonio y a la residencia separada de ambos en distintos países, ambos cónyuges llevan seis años sin convivencia conyugal, figurando el domicilio conyugal en la C/Salitre $n^{\circ}$ 6, en Madrid, España

Como fundamento de los hechos anteriores se adjuntan a la presente demanda los siguientes documentos: - Certificación de la Inscripción en el Registro Civil y -Certificaciones registrales de los nacimientos de los hijos comunes.

A los anteriores hechos son de aplicación los siguientes

\section{Fundamentos de derecho}

Primero. La representación del actor y la postulación a la presente demanda es la procedente conforme al art. 750 y siguientes de la Ley de Enjuiciamiento Civil 2000.

Segundo. En cuanto a la Competencia Judicial Internacional, este es un caso que puede decidirse conforme al art. 2.1 a) del Reglamento comunitario 1347/2000 de 29 de mayo relativo a la competencia, el reconocimiento y la ejecución de resoluciones judiciales en materia matrimonial y de responsabilidad parental sobre los hijos comunes, de ahora en adelante, el Reglamento de Bruselas II. No es posible aplicar el art. $22 \mathrm{LOPJ}$, porque el Reglamento citado ha desactivado los foros de competencia autónomos, aplicándose de forma preferente a estos cuando, como en el caso, se cumplen varias de los foros objetivos de competencia judicial internacional contemplados en el art. 2.1 a) del Reglamento. Son foros que operan con carácter alternativo. Basta con que concurran uno de los foros previstos en el convenio para que los tribunales del país del que se trate se declaren competentes. Cosa que ocurre en el supuesto, puesto que España ha sido el país de la última residencia habitual de los cónyuges y la demandante reside en España y, además, ha adquirido la nacionalidad española en el momento de presentación de la demanda. El juez ante el que se presenta la demanda de divorcio, separación o nulidad debe comprobar su competencia de oficio.

Tercero. En cuanto a la competencia territorial se interesa la aplicación del art. 769 LEC, que hace competente al juez correspondiente al domicilio del actor en España, toda vez que el demandado no reside en España. Se interesa igualmente la aplicación del art. 770 LEC 2000, que regula el procedimiento a seguir en la presente demanda de divorcio por vía contenciosa.

Cuarto. En cuanto a la ley aplicable, de acuerdo con el art. 107. 2 Cc reformado por la Ley Orgánica 11/2003, de 29 de septiembre, se interesa la aplicación de la ley española por los siguientes motivos: Al haber adquirido la demandante la nacionalidad española los cónyuges ya no tienen nacionalidad común al tiempo de presentación de la demanda, por lo que, a falta de ley nacional común, será de aplicación la ley de la residencia habitual del matrimonio, es decir, la ley española. $Y$, en concreto, el art. 85 Cc. En cuanto a la disolución del matrimonio por divorcio.

Quinto. En cuanto a las causas del divorcio se invoca el art. $86 \mathrm{Cc}$.

Sexto. Debe ser parte el ministerio Fiscal, al ser todavía menores los hijos habidos en el matrimonio.

Séptimo. Se interesa la aplicación del art. 394 LEC que regula las costas que deben imponerse al demandado para el caso de oposición.

En atención a lo anteriormente expuesto:

\section{Suplico al juzgado}

Que teniendo por presentado este escrito de demanda junto a los documentos y copias que se acompañan, tenga a bien admitirla, y tener por formulada, por consiguiente, demanda de divorcio de D. (...) contra su esposo (...) y cumplidos los trámites pertinentes como es el recibimiento a prueba, que desde ya se solicita, tenga a bien dictar en su día sentencia por la que se declare la disolución del matrimonio por divorcio, de mi representada Dña. María G.R. y D Miguel P.N.

Es justicia que pido en la ciudad de Madrid a 8 de enero de 2004.

Fdo. Letrado

Fdo. Procurador 
en materia matrimonial se ha aplicado el procedimiento estándar de exequátur. Cuya novedad principal es que, a partir de 2004 y gracias a las recientes reformas operadas por la Ley Orgánica 19/2003 y por la Ley 62/2003, ya no será llevado a cabo ante el Tribunal Supremo, sino por los Juzgados de Primera Instancia, con el ahorro de tiempo que ello tiene previsto conllevar. Ahora bien, por el momento, es demasiado pronto para saber si será ésta una medida que dé el fruto deseado en la práctica por lo que se estará a la espera de cómo trascurre y se desarrolle esta nueva posibilidad de lege ferenda.

En conclusión, en relación con la aplicación de la normativa comunitaria en materia matrimonial a los ciudadanos/as ecuatorianos/as residentes en España, se ha de hacer una importante diferenciación entre el sector de la compe- tencia y el del reconocimiento y ejecución. Las normas de competencia son susceptibles de amparar a un residente ecuatoriano por el simple hecho de residir en un país europeo como España. La llamada conexión comunitaria será suficiente para fundamentar la competencia de los jueces y tribunales españoles sobre la base del nuevo Reglamento de Bruselas II, art. 3. 1 a), ex. art. 2.1 a) RB II, para decidir de un supuesto de nulidad, separación o divorcio, aunque el cónyuge del ecuatoriano demandado se encuentre en un país no comunitario como Ecuador. Sin embargo, en cuanto al reconocimiento de las decisiones dictadas en materia matrimonial, el Reglamento sólo se aplicará al reconocimiento de decisiones comunitarias en el marco comunitario.

1. Oficina de Relaciones Informativas y Sociales, correo electrónico: serviprs@documenta.mir.es

2. Publicado en el Diario Oficial de la Comunidad Europea, DOCE, L 160 de 30 de junio de 2000 .

3. Publicado, como el anterior en el DOCE, actual Diario Oficial de la Unión europea, DOUE L 338/1 de 23 de diciembre de 2003.

4 Sobre la simple conexión comunitaria como criterio de aplicación del Reglamento de Bruselas II, vid. E. Rodríguez Pineau, El nuevo Reglamento Comunitario sobre litigios matrimoniales y responsabilidad parental, La Ley, Unión Europea, núm. 5944, viernes 30 de enero de 2004, p. 2.

5 Boletín Oficial del Estado Español -BOE-, núm. 157, de 2 de julio; corr. de errores en el BOE núm. 264, de 4 de noviembre de 1985.

6 Gaceta de Madrid de 25 de julio de 1889.

7 BOE núm. 7, de 8 de enero de 2000; corr. de errores, BOE núm. 90, de 13 de abril.

8 BOE, de 30 de septiembre de 2003.

9 Sobre las modificaciones producidas por dichos cambios, vid. infra., el epígrafe V.

10 Estos Convenios, respectivamente, son los siguientes: Convenio bilateral firmado entre España y: 1. Suiza: Tratado sobre la ejecución de sentencias en materia civil y comercial entre España y Suiza, hecho en Madrid el 10 de noviembre de 1986 (Gaceta de Madrid de 9 de julio de 1898). 2. Colombia: Convenio sobre ejecución de sentencias civiles entre España y Colombia, hecho en Madrid el 30 de mayo de 1908 (Gaceta de Madrid de 18 de abril de 1909). 3. República Checa y Eslovaquia: Convenio sobre asistencia jurídica, reconocimiento y ejecución de sentencias en asuntos civiles entre España y Checoslovaquia, hecho en Madrid el 4 de mayo de 1987 (BOE núm. 290 de 3 de diciembre de 1988 y corrección de errores en el BOE núm. 22 de enero de 1989 , completado con intercambio de notas de 21 de marzo de 1994 y 2 de febrero de 1995, por el que tanto la República Checa como Eslovaquia declaran la vigencia de este Convenio para sus respectivos países, siendo la entrada en vigor el 10 de diciembre de 1988). 4. México: Convenio sobre reconocimiento y ejecución de sentencias judiciales y laudos arbitrales, en materia civil y mercantil entre España y México, hecho en Madrid el 17 de abril de 1989 (BOE núm. 108 de 6 de mayo de 1991 y BOE núm. 226 de 20 de septiembre de 1991). 5. Israel: Convenio entre España e Israel para el mutuo reconocimiento y la ejecución de sentencias en materia civil y mercantil hecho en Jerusalén el 30 de mayo de 1989 (BOE núm. 3 de 3 de enero de 1991 y corrección de errores en el BOE núm. 20 de enero de 1991, entrada en vigor el 13 de enero de 1991). 6. Brasil: Convenio de cooperación jurídica en materia civil entre España y Brasil, hecho en Madrid, el 13 de abril de 1989. (BOE núm. 164 de 10 de julio de 1991 y corrección de errores en el BOE núm. 193 de 13 de agosto) 7. Bulgaria: Convenio de asistencia judicial en materia civil entre el Reino de España y la República de Bulgaria, hecho en Sofía el 23 de mayo de 1993 (BOE núm. 155 de 30 de junio de 1994). 8. China: Tratado entre el Reino de España y la República Popular China sobre asistencia judicial en materia civil y mercantil, hecho en Pekín el 2 de mayo de 1992 (BOE núm. 26 de 31 de enero de 1994 y corrección de errores en el BOE núm. 60 de 11 de marzo de 1994, entrada en vigor el 1 de enero de 1994). 9. Rusia: 
Notas Convenio entre España y la Unión de Repúblicas Socialistas Soviéticas sobre asistencia judicial en materia civil, firmado en Madrid, el 26 de octubre de 1990 (BOE núm. 151 de 25 de junio de 1997. En la actualidad, el Convenio debe entenderse en vigor entre España y Rusia. Entrada en vigor, el 22 de julio de 1997). 10. Marruecos: Convenio de cooperación judicial en materia civil, mercantil y administrativa entre el Reino de España y el Reino de Marruecos, firmado en Madrid el 30 de mayo de 1997 (BOE núm. 151 de 25 de junio de 1997. Entrada en vigor de 1 de julio de 1999). 11. Uruguay: Convenio de cooperación jurídica entre el Reino de España y la República oriental de Uruguay hecho en Montevideo el 4 de noviembre de 1987 (BOE núm. 103 de 30 de abril de 1998. Entrada en vigor el 30 de abril de 1998). Y, 12, el más reciente, firmado con Rumania: Convenio entre España y Rumania sobre competencia judicial, reconocimiento y ejecución de decisiones en materia civil y mercantil, hecho ad referéndum en Bucarest el 17 de noviembre de 1997 (BOE núm. 134 de 5 de junio de 1999 y BOE núm. 158 de 3 de julio de 1999. Entrada en vigor el 13 de junio de 1999).

11 Sobre el forum shopping en el marco del Derecho internacional de familia y los numerosos intentos para evitarlo en la jurisprudencia española, vid. el Auto de la Audiencia Provincial de Madrid de 21 de febrero de 1997, REDI, vol. L (1998), 1 con nota de F. Esteban de la Rosa, id. cit., pp. 283-287.

12 DOCE núm. C 27, de 26 de enero de 1998.

13 Informe explicativo del mismo a cargo de la catedrática de Derecho Internacional Privado Dña. Alegría Borrás Rodríguez, DOCE, C 221, de 16 de julio de 1998, pp. 27-64.

14 DOCE núm. L 012, de 16 de enero de 2001; corr de errores, DOCE núm. L 307, de 24 de noviembre; DOCE núm. L. 176, de 5 de julio de 2002.

15 En relación con las críticas referidas al estrecho margen de aplicación del Reglamento, vid. R. Caro Gandara, Algunos problemas derivados del ámbito de aplicación personal del Reglamento 1347/2000 de 29 de mayo relativo a la competencia, el reconocimiento y la ejecución de resoluciones judiciales en materia matrimonial y de responsabilidad parental sobre los hijos comunes, SEPIN, Revista de Derecho de Familia, núm. 14, 2002, pp. 259-257, J. Carrascosa, Cuestiones polémicas en el Reglamento $1347 / 2000$ en AA.VV., Mundialización y Familia, Colex, Madrid, 2001, pp. $213-$ 239; B. Ancel y H. Muir-Watt, La désunion européenne: le règlement dit Bruxelles II, R.C.D.I.P., 2001, PP. 403-457, Gaudemet-Tallon, Le Réglement núm. 1347/2000 du Conseil du 29 du mai: Compétence, reconnaissance et exécution des décisions en matiére matrimoniale et en matière de responsabilité parentale des enfants communs, Journ. dr. int., 2001-2, pp. 382-430 y A.L. Calvo Caravaca y J. Carrascosa González, Derecho de Familia Internacional, Madrid, Colex, 2004.

$16 \operatorname{COM}$ (2002) 222 final/2 -2002/0110 (CNS).

17 DOCE núm. C 61, de 14 de marzo de 2003.

18 Dando cuenta de los escasos cambios sustanciales susceptibles de ser producidos por la Propuesta y las diferencias que ello podría conllevar en relación con el Reglamento de Bruselas II, vid. M. Gonzalo Quiroga, Cuadros de aplicación práctica ante la Propuesta de Reglamento en materia matrimonial y de responsabilidad parental derogando el Reglamento CE $n^{\circ}$. 1347/2000 y modificando el Reglamento $C E n^{\circ}$. 44/2001 en materia de alimentos, SEPIN, Revista de Familia, julio-agosto 2003, núm. 24, pp. 39-46. Refiriéndose, en concreto, a las ampliaciones del ámbito de aplicación material y a las correcciones técnicas al Reglamento 1347/2000, cf., E. Rodríguez Pineau, El nuevo Reglamento..., loc. cit., pp. 4-8.

19 Sobre el particular, vid. E. Rodríguez Pineau, El nuevo Reglamento..., loc. cit., p. 14.

20 País que voluntariamente se ha quedado fuera del Reglamento al rechazar la aplicación del Título IV del Tratado constitutivo de la Comunidad Europea (TCE). Título en el que, precisamente, se ha basado la cimentación del Reglamento. Sobre el caso danés y Bruselas II, en general, vid. el trabajo de A. Borras Rodríguez, Informe explicativo del Convenio..., op. cit., pp. 27-64.

21 Vid. Infra. Los casos en los que el Reglamento de Bruselas II desactiva los foros de competencia del régimen autónomo español previstos en el art. 22 LOPJ.

22 A los efectos de la aplicación del Reglamento se entiende por domicile en el mismo sentido que dicho término tiene con arreglo a los ordenamientos jurídicos del Reino Unido y de Irlanda, art. 3. 2 del nuevo RB II, art. 2.2 del anterior. 
Notas 23 Para mayor información sobre el particular en cuanto a la competencia territorial interna, vid. A.L.Calvo Caravaca y J. Carrascosa González, Práctica Procesal Civil Internacional, Granada, Comares, 2001, pp. 141-142, apartado 26.

24 Desactivación de los foros de competencia por actuación del Reglamento comunitario original de A.L. Calvo Caravaca y J. Carrascosa González, Práctica Procesal Civil Internacional, op. cit., pp. 140-141. En contra, Sánchez Jiménez, Mª.A., loc. cit., p. 198.

25 En este sentido la Ley española en materia de nacionalidad ha sido reformada por la Ley 36/2002, de 8 de octubre, de modificación del Código Civil en materia de nacionalidad, $\mathrm{BOE} \mathrm{n}^{\circ} 242$, de 9 de octubre de 2002.

26 Argumento que erróneamente sostuvo la Sentencia del Juzgado de Primera Instancia de Estepona de 23 de febrero de 1990 y la Sentencia de la Audiencia Provincial de Granada de 14 de enero de 1991.

27 Cf. A.L. Calvo Caravaca y J. Carrascosa González, Práctica..., op. cit., p. 141.

28 Así ha sido reflejado en los siguientes Autos y sentencias dictados por Jueces y Tribunales españoles, Sentencia de la Audiencia Provincial de Asturias de 12 de diciembre de 1994, Auto de la Audiencia Provincial de Madrid, de 21 de febrero de 1997, Auto de la Audiencia Provincial de Madrid, de 28 de febrero de 1997 y Auto de la Audiencia Provincial de Madrid, de 27 de febrero de 1998: (...) Los órganos jurisdiccionales españoles tienen jurisdicción en el proceso matrimonial cuando las partes se han sometido a ellos, expresa o tácitamente, o bien cuando la parte demandada tenga el domicilio en España, (Ar. Civ. 448).

29 Sobre la discriminación por razones de nacionalidad introducidas por Bruselas II, vid. el trabajo de M. Gómez Jene, El Reglamento comunitario en materia matrimonial: criterio de aplicación personal, privilegios de los nacionales comunitarios y discriminación por razón de la nacionalidad, La Ley, núm. 5321, 2001, pp. 1-8.

30 Vid. los comentarios al respecto y la jurisprudencia enunciada por Vargas Gómez Urrutia, M., Matrimonio poligámico, orden público y extranjería, La Ley, 11 de septiembre de 2003, p. 8.

31 Cf. E. Pérez Vera (directora), A.P. Abarca Junco., M. Gómez Jene, M. Guzmán Zapater y P.P. Miralles Sangro, Derecho Internacional Privado, vol. II, Madrid, UNED, 2001, pp. 151-155.

32 Id. cit., p. 156.

33 Poniendo de relieve la difícil comparación que en el marco del reconocimiento y ejecución de sentencias en Derecho internacional de familia se da entre aquellos países comunitarios que entran en el reconocimiento de Bruselas II y el resto de sistemas que carecen de una normativa específica en este ámbito, vid. TH. M. De Boer, Jurisdiction and Enforcement in International Family Law: A Labyrinth of European and International Legislation, NILR, 2002, pp. 307-353.

34 Sobre el particular, vid. M. Herranz Ballesteros, Primeros pasos de la práctica registral española en la aplicación del Reglamento en materia matrimonial: reflexiones al hilo de la Resolución de la DGRN de 4 de mayo de 2002, La Ley, 10 de febrero de 2003, pp.1-7; y el estudio coordinado por S. Salvador Gutiérrez, Aplicación en el Registro Civil del Reglamento Comunitario 347/2000, de 29 de mayo de 2000, SEPIN, Noviembre 2002, núm. 16, Familia, pp. 79-84, sobre la interpretación de las dudas planteadas en relación con la actualización de los datos registrales por los magistrados/as encargados del Registro Civil de Madrid, Bilbao, Málaga, Barcelona y Sevilla. 